\title{
The Effect of the COVID 19 Pandemic on Elective Surgical Services in Jos, North Central, Nigeria
}

\author{
Michael Bundepuun Ode ${ }^{\text {1* }}$ Andrew Shitta', Solomon Danjuma Peter², Idumagbodi Amupitan1, \\ Shem Bulus Yilleng1
}

${ }^{1}$ Department of Orthopaedics and Trauma, College of Health sciences, Jos University Teaching Hospital, Jos, Nigeria

${ }^{2}$ Department of Surgery, College of Health sciences, Jos University Teaching Hospital, Jos, Nigeria

Email: *odemb2014@gmail.com

How to cite this paper: Ode, M.B., Shitta, A., Peter, S.D., Amupitan, I. and Yilleng, S.B. (2021) The Effect of the COVID 19 Pandemic on Elective Surgical Services in Jos, North Central, Nigeria. Journal of Biosciences and Medicines, 9, 29-37. https://doi.org/10.4236/jbm.2021.97005

Received: June 2, 2021

Accepted: July 9, 2021

Published: July 12, 2021

Copyright $\odot 2021$ by author(s) and Scientific Research Publishing Inc. This work is licensed under the Creative Commons Attribution International License (CC BY 4.0).

http://creativecommons.org/licenses/by/4.0/

\begin{abstract}
Background. The COVID 19 pandemic affected healthcare delivery systems worldwide. There was a redistribution of health care resources in order to deal with the effects of the pandemic, with a corresponding consequence on other clinical services rendered. The extent of this effect on other non COVID 19 related services has been reported in other centres worldwide. In our own setting, health care resources are limited with suboptimal access even in normal situations. Objective. We sought to evaluate the effects of the COVID 19 pandemic on elective surgical services in our hospital. Methods. This was a cross sectional comparative study carried out at the Jos University Teaching hospital, (North central, Nigeria) of the elective surgical services rendered during the first wave of the COVID 19 pandemic lockdown covering the period April to June 2020 with a corresponding period of the preceding year 2019. Data was obtained from the hospital records department, theatres and service areas for clinic attendance, elective surgeries and ward occupancy. The paired sample t-test was used to compare the assessed variables across the three months of both years with a level of significance of $\mathrm{P}<0.05$. Results. There was mean clinic attendance of $2859.33 \pm 223.36$ covering the three months in 2019 as against a mean attendance of $648.67 \pm 578.24$ covering a similar period in $2020, \mathrm{P}=0.037$. The elective surgical procedures carried out across the surgical specialties over the period in 2019 gave a mean of $352.33 \pm 44.60$ as opposed to $64.001 \pm 7.32$ over the corresponding period in $2020, P=0.018$. Ward occupancy over April to June 2019 was a mean 297.33 \pm 18.58 across the various surgical wards and $158.33 \pm 25.70$ in the same period in 2020, $\mathrm{P}=0.007$. Conclusion. There was a significant reduction in the elective surgical services rendered in the hospital during the first wave of the COVID 19 pandemic compared to a corresponding period in the preceding
\end{abstract}


year. This decline in elective surgical services would have negatively affected the access to health care. Thus measures to clear the backlog of elective surgical procedures would be required.

\section{Keywords}

COVID 19, Lockdown, Elective Surgery, Clinic Attendance, Ward Occupancy, Jos

\section{Introduction}

The COVID 19 virus infection was declared a pandemic by the WHO on the $11^{\text {th }}$ of March 2020 [1]. There was a rapid spread in Asia, Europe the United States and then Africa [2] [3] [4]. Nigeria reported its first case in February 2020 [5] [6]. This was a novel virus and the clinicians and scientists had no prior experience with this virus. It resulted in an avalanche of infected people requiring medical attention. Various mitigation measures were adopted globally to limit the spread of the disease. Measures ranged from flight restrictions, various degrees of population lockdowns to the personal measures of social distancing, wearing of face masks and frequent hand washing [2] [3]. Politicians and clinicians were in a race to get a better understanding of the virus, its modes of spread and effective prevention methods.

The virus spread and resulted in a marked upsurge in hospitalizations and deaths worldwide, stretching health care services to a breaking point, even in countries with very robust health care infrastructures [7]. There was thus a redistribution of health care resources to cater to the burgeoning number of COVID 19 infections to the detriment of other services [8] [9] [10]. There was pressure on bed spaces, ICU beds, Oxygen supply, critical care physicians and intensivists [11]. There was the recruiting of unspecialised personnel to care for patients with COVID due to shortages [12]. Due to the evolving understanding of the methods of spread of the virus, there were multiple advisories to surgeons to be careful in carrying out surgical procedures to limit the spread of the infection, particularly within the hospital setting which would further reduce the available medical manpower [9] [13] [14] [15]. The acute shortage of personal protective equipment (PPE) also limited the conduct of a wide range of clinical care as the few available were redirected towards managing patients suspected or confirmed to have COVID 19. Face masks which were hitherto available at every unit in hospitals, were now a scarce commodity. The N95 respirators that ensured a higher level of protection were suddenly in very short supply due to the demand which had skyrocketed [16] [17]. The total lockdowns which were instituted also restricted movement within cities and neighbourhoods preventing the population from visiting the hospitals for their routine medical care as only emergency cases frequented the hospitals [18]. There were also cancellations of clinic visits, and surgical lists were suspended in some instances [19] [20]. The 
lockdown which limited movement also resulted in a decrease in trauma cases and trauma referrals as vehicular and other movements were restricted [21].

There was also a reluctance of patients to visit hospitals as it was assumed that there was a high risk of contracting the virus in the hospital environment, as this was where infected patients were treated and susceptible health care workers were a teeming number [22]. The cumulative effect of the redistribution of health resources, the limitation in movement and the fear of the hospital environment resulted in a decline in surgical services [23] [24] [25]. In our environment with an already existing limitation in the availability and access to health care even before the onset of COVID 19, the restrictions placed to mitigate the spread of the virus would further we believe result in a limitation to utilization of these health care services as had been observed in some countries [26] [27]. We thus set out to examine the effect of the COVID 19 pandemic on elective surgical services rendered in our facility.

\section{Methods}

This was a cross sectional comparative study carried out at the Jos University Teaching hospital of the elective surgical services rendered during the first wave of the COVID 19 pandemic covering the period April to June 2020 with a corresponding period of the preceding year 2019 covering the same period April to June. The services evaluated were; surgical clinics, elective surgical procedures and the ward occupancy during the periods under review. Data was retrospectively obtained from the hospital records department for clinic attendances, surgical operations and ward occupancy, covering the period in view for both years. The data was compared across surgical subspecialties for each of the three months of both years across the services of outpatient clinics, elective surgical procedures and ward occupancy. Emergency services were not included. The Paired sample t-test was used to compare the assessed variables across the three months of both years with a level of significance of $\mathrm{P}<0.05$. SPSS version 23 was used in analysis.

\section{Results}

There were a total of 8578 surgical clinic visits between April and June of 2019 and 1946 visits in the corresponding period of 2020 (Table 1), giving a 77.3\% reduction in clinic visits. There was a mean clinic attendance of $2859.33 \pm 223.36$ covering the three months in 2019 as against a mean attendance of $648.67 \pm$ 578.24 covering a similar period in $2020, \mathrm{P}=0.037$. There were 2910 clinic visits in the month of May 2019 and 109 in May 2020. 96.2\% reduction.The elective surgical procedures carried showed a 76.4\% reduction from a total of 1057 for the period in 2019 down to a total of 249 in 2020 (Table 2). A mean of elective surgical procedures was $352.33 \pm 44.60$ in 2019 as opposed to $64.001 \pm 7.32$ over the corresponding period in $2020, \mathrm{P}=0.018$. General surgery, Neurosurgery, Orthopaedic and Paediatric surgical procedures, made up 35.3\% of the surgical 
procedures which were the specialties with the most procedures in 2020 Cardiothoracic, Plastic and Urological procedures accounted for $6.8 \%$ of the surgical procedures in 2020 the least. Within the period in 2019, there was a similar output amongst the specialties. There was an $84.9 \%$ reduction of elective surgeries in the month of May from 403 procedures in 2019 to 61 in 2020 . Ward occupancy in 2020 for the period was 475 and 892 in 2019 (Table 3). 44.5\% reduction. Ward occupancy over April to June 2019 gave a mean of $297.33 \pm 18.58$ across the various surgical wards and $158.33 \pm 25.70$ in the same period in 2020, $\mathrm{P}=0.007$ (Table 4). There was a 52.9\% reduction in ward admission in the month of April from 306 in 2019 to 144 in 2020.

Table 1. Clinic attendance.

\begin{tabular}{ccccccc}
\hline \multirow{2}{*}{ Clinic Attendance } & \multicolumn{2}{c}{2019} & \multicolumn{2}{c}{2020} & \multicolumn{2}{c}{ Total } \\
\cline { 2 - 7 } & N & $(\%)$ & N & $(\%)$ & N & $(\%)$ \\
\hline April & 3053 & $(84.1)$ & 578 & $(15.9)$ & 3631 & $(100)$ \\
May & 2910 & $(96.4)$ & 109 & $(3.6)$ & 3019 & $(100)$ \\
June & 2615 & $(67.5)$ & 1259 & $(32.5)$ & 3874 & $(100)$ \\
Total & $\mathbf{8 5 7 8}$ & $(\mathbf{8 1 . 5 )}$ & 1946 & $(18.5)$ & 10,524 \\
\hline
\end{tabular}

Table 2. Elective Surgical procedures.

\begin{tabular}{ccccccc}
\hline \multirow{2}{*}{ Operations } & \multicolumn{2}{c}{2019} & \multicolumn{2}{c}{2020} & \multicolumn{2}{c}{ Total } \\
\cline { 2 - 7 } & $\mathbf{N}$ & $(\%)$ & $\mathbf{N}$ & $(\%)$ & N & $(\%)$ \\
\hline April & 319 & $(77.2)$ & 94 & $(22.8)$ & 413 & $(100)$ \\
May & 403 & $(86.9)$ & 61 & $(13.1)$ & 464 & $(100)$ \\
June & 335 & $(78.1)$ & 94 & $(21.9)$ & 429 & $(100)$ \\
Total & 1057 & $(80.9)$ & $\mathbf{2 4 9}$ & $(19.1)$ & \multicolumn{2}{c}{$\mathbf{1 3 0 6}$} \\
\hline
\end{tabular}

Table 3. Ward occupancy.

\begin{tabular}{ccccccc}
\hline \multirow{2}{*}{ Wards } & \multicolumn{2}{c}{2019} & \multicolumn{2}{c}{2020} & \multicolumn{2}{c}{ Total } \\
\cline { 2 - 7 } & $\mathbf{N}$ & $(\%)$ & $\mathbf{N}$ & $(\%)$ & $\mathbf{N}$ & $(\%)$ \\
\hline April & 306 & $(68.0)$ & 144 & $(32.0)$ & 450 & $(100)$ \\
May & 276 & $(65.9)$ & 143 & $(34.1)$ & 419 & $(100)$ \\
June & 310 & $(62.2)$ & 188 & $(37.8)$ & 498 & $(100)$ \\
Total & $\mathbf{8 9 2}$ & $(65.3)$ & $\mathbf{4 7 5}$ & $(34.7)$ & \multicolumn{2}{|c}{$\mathbf{1 3 6 7}$} \\
\hline
\end{tabular}

Table 4. Comparing the Elective surgical services between the periods.

\begin{tabular}{cccccc}
\hline Variable & Mean 2019 & Mean 2020 & t & df & p \\
\hline Clinic attendance & $2859.33 \pm 223.36$ & $648.67 \pm 578.24$ & 5.052 & 2 & 0.037 \\
Operations & $352.33 \pm 44.60$ & $64.001 \pm 7.32$ & 7.354 & 2 & 0.018 \\
Ward Occupancy & $297.33 \pm 18.58$ & $158.33 \pm 25.70$ & 11.651 & 2 & 0.007 \\
\hline
\end{tabular}




\section{Discussion}

The COVID 19 pandemic resulted in an upsurge in hospital admissions and a sudden increase in hospital service utilization. The sudden increased demand on healthcare resources led to a skewed distribution of these services in favour of COVID 19 infections [13]. As a consequence of this redistribution, other health services were impacted [28]. Elective surgical services which was the thrust of our investigation was also affected by various advisories curtailing these procedures as well as the difficulty posed by the various lockdowns which attempted to mitigate the spread of the virus [9] [15].

In our study, where we sought to determine the effect of the pandemic on elective surgical practice, we found a significant reduction in the volume of elective surgical services rendered during the months of April to June 2020 when there were total lockdowns in Nigeria, compared to a corresponding period in the preceding year. There was a $77.3 \%$ reduction in surgical outpatient visits during the period in 2020. There was a mean clinic attendance of $648.67 \pm$ 578.24 in 2020 compared with a mean of $2859.33 \pm 223.36$ in $2019, \mathrm{P}=0.037$. The lockdowns instituted, which severely limited movement can be considered responsible for this significant reduction. Though people on their way to hospital would not be turned back, the restriction on public transportation could have hampered the ability of patients getting to the clinics. The outpatient clinics also rescheduled a lot of appointments and out rightly cancelled others to limit the numbers at the clinics in an attempt to mitigate the spread of the virus. This reduction in clinic visits was noticed by other investigators [12] [29].

There was a $76.4 \%$ reduction in elective surgical procedures carried out in the period under investigation in 2020 compared to the corresponding period in 2019. A mean number of $352.33 \pm 44.60$ in 2019 as opposed to $64.001 \pm 7.32$ in $2020, \mathrm{P}=0.018$. Ayyaz $\mathrm{M}$ et al. in their study found a $66 \%$ decline in elective surgeries during the pandemic [30]. Several factors may have contributed to this significant decline in elective operations. The reduced attendance at the outpatient clinics, the pool from which elective surgeries are booked would have contributed to the lower number of cases scheduled for surgery. The evolving knowledge on the modes of spread of the virus at the time, led to multiple advisories from; surgical societies, government agencies and hospital managements on the need to tail down operative surgical procedures. This resulted in a limitation of such procedures with emergencies largely being attended to. Some investigators also reported declines in surgical output during the lockdowns [12] [31]. Laas, D.J et al. reported a decline of $30 \%$ in surgical procedures [26].

Ward occupancy between April and June 2019 was a mean of $297.33 \pm 18.58$ across the various surgical wards and $158.33 \pm 25.70$ in the same period in 2020, $\mathrm{P}=0.007$. The ward occupancy is due to cases from emergencies and elective procedures. The significant decline is attributable to the reduction in elective surgical procedures. The reduction in the ward occupancy of $46.7 \%$ in 2020 is not as marked as the reduction in the clinic attendances and surgical procedures 
presumably due to the fact that emergency surgical procedures were being carried out, which contributed to the ward occupancy. Similar studies in South Africa showed a significant reduction in admissions not due to trauma during the lockdown with a $44 \%$ reduction in such admissions [2].

The above findings show an overall significant reduction in elective surgical services in our institution during the COVID 19 lockdown as compared to a similar period in the preceding year. This situation was not peculiar to our facility. Other researchers have reported a decline in surgical services as well during the lockdown periods [12] [30] [32].

\section{Conclusion}

There was a significant reduction in the elective surgical services rendered in the hospital during the first wave of the COVID 19 pandemic compared to a corresponding period in the preceding year. This decline in elective surgical services would have negatively affected the access to health care, thus measures to clear the backlog of elective surgical procedures would be required.

\section{Limitations}

There was the possibility of missed data due to the retrospective collection and the figures from the ward occupancy may overlap due to patients with prolonged hospitalization.

\section{Conflicts of Interest}

The authors declare no conflicts of interest regarding the publication of this paper.

\section{References}

[1] Sanyaolu, A., Okorie, C., Hosein, Z., Patidar, R., Desai, P., Prakash, S., et al. (2021) Global Pandemicity of COVID-19: Situation Report as of June 9, 2020. Infectious Diseases, 14. https://doi.org/10.1177/1178633721991260

[2] Moustakis, J., Piperidis, A.A. and Ogunrombi, A.B. (2020) The Effect of COVID-19 on Essential Surgical Admissions in South Africa: A Retrospective Observational Analysis of Admissions before and during Lockdown at a Tertiary Healthcare Complex. South African Medical Journal, 110, 910-915. https://doi.org/10.7196/SAMJ.2020.v110i9.15025

[3] Mishra, D., Nair, A.G., Gandhi, R.A., Gogate, P.J., Mathur, S., Bhushan, P., et al. (2020) The Impact of COVID-19 Related Lockdown on Ophthalmology Training Programs in India-Outcomes of a Survey. Indian Journal of Ophthalmology, 68, 999-1004. https://doi.org/10.4103/ijo.IJO_1067_20

[4] Sun, H., Dickens, B.L., Cook, A.R. and Clapham, H.E. (2020) Importations of COVID-19 into African Countries and Risk of Onward Spread. BMC Infectious Diseases, 20, 598. https://doi.org/10.4103/ijo.IJO_1067_20

[5] Adebowale, A.S., Fagbamigbe, A.F., Akinyemi, J.O., Obisesan, O.K., Awosanya, E.J., Afolabi, R.F., et al. (2021) The Spread of COVID-19 Outbreak in the First 120 Days: A Comparison between Nigeria and Seven Other Countries. BMC Public Health, 21, 129. https://doi.org/10.1186/s12889-020-10149-x 
[6] Onyeaghala, A.A. and Olajide, I. (2020) Managing COVID-19 Outbreak in Nigeria: Matters Arising. Clinical Chemistry and Laboratory Medicine, 58, 1645-1650. https://doi.org/10.1515/cclm-2020-0748

[7] Shah, S., Castro-Dominguez, Y., Gupta, T., Attaran, R., Byrum, G.V., Taleb, A., et al. (2020) Impact of the COVID-19 Pandemic on Interventional Cardiology Training in the United States. Catheterization and Cardiovascular Interventions, 96, 997-1005. https://doi.org/10.1002/ccd.29198

[8] Graetz, D., Agulnik, A., Ranadive, R., Vedaraju, Y., Chen, Y., Chantada, G., et al. (2021) Global Effect of the COVID-19 Pandemic on Paediatric Cancer Care: A Cross-Sectional Study. The Lancet Child \& Adolescent Health, 5, 332-340. https://doi.org/10.1016/S2352-4642(21)00031-6

[9] Fowler, S., Zahir, S.F., Manning, W., Kearney, A. and Sturgess, D. (2021) Effect of the COVID-19 Pandemic First Wave and Public Policy on Elective and Emergency Surgery Provision in Southern Queensland. ANZ Journal of Surgery, 91, 249-254. https://doi.org/10.1111/ans.16568

[10] Haut, E.R., Leeds, I.L. and Livingston, D.H. (2020) The Effect on Trauma Care Secondary to the COVID-19 Pandemic: Collateral Damage From Diversion of Resources. Annals of Surgery, 272, e204-e207. https://doi.org/10.1097/SLA.0000000000004105

[11] Tan, E., Song, J., Deane, A.M. and Plummer, M.P. (2021) Global Impact of Coronavirus Disease 2019 Infection Requiring Admission to the ICU: A Systematic Review and Meta-Analysis. Chest, 159, 524-536. https://doi.org/10.1016/j.chest.2020.10.014

[12] Chu, K.M., Smith, M., Steyn, E., Goldberg, P., Bougard, H. and Buccimazza, I. (2020) Changes in Surgical Practice in 85 South African Hospitals during COVID-19 Hard Lockdown. South African Medical Journal, 110, 916-919. https://doi.org/10.7196/SAMJ.2020.v110i9.15014

[13] Shakir, T., Iqbal, M.R., Darwish, N.M. and Kirmani, N. (2021) Lessons for Emergency Surgery in the Second Wave: One-Month Single-Centre Experience during the First Wave of COVID-19. Cureus, 13, e12685.

https://doi.org/10.7759/cureus.12685

[14] Soreide, K., Hallet, J., Matthews, J.B., Schnitzbauer, A.A., Line, P.D., Lai, P.B.S., et al. (2020) Immediate and Long-Term Impact of the COVID-19 Pandemic on Delivery of Surgical Services. The British Journal of Surgery, 107, 1250-1261. https://doi.org/10.1002/bjs.11670

[15] Ghai, S. (2020) Will the Guidelines and Recommendations for Surgery during COVID-19 Pandemic Still Be Valid If It Becomes Endemic? International Journal of Surgery, 79, 250-251. https://doi.org/10.1016/j.ijsu.2020.06.011

[16] Ogoina, D. (2020) COVID-19: The Need for Rational Use of Face Masks in Nigeria. The American Journal of Tropical Medicine and Hygiene, 103, 33-34. https://doi.org/10.4269/ajtmh.20-0433

[17] Odusanya, O.O., Odugbemi, B.A., Odugbemi, T.O. and Ajisegiri, W.S. (2020) COVID-19: A Review of the Effectiveness of Non-Pharmacological Interventions. The Nigerian Postgraduate Medical Journal, 27, 261-267. https://doi.org/10.4103/npmj.npmj_208_20

[18] McLean, R.C., Young, J., Musbahi, A., Lee, J.X., Hidayat, H., Abdalla, N., et al. (2020) A Single-Centre Observational Cohort Study to Evaluate Volume and Severity of Emergency General Surgery Admissions during the COVID-19 Pandemic: Is There a "Lockdown" Effect? International Journal of Surgery, 83, 259-266. https://doi.org/10.1016/j.ijsu.2020.09.011 
[19] Topriceanu, C.C., Wong, A., Moon, J.C., Hughes, A.D., Bann, D., Chaturvedi, N., et al. (2021) Evaluating Access to Health and Care Services during Lockdown by the COVID-19 Survey in five UK National Longitudinal Studies. BMJ Open, 11, e045813. https://doi.org/10.1136/bmjopen-2020-045813

[20] Morris, E.J.A., Goldacre, R., Spata, E., Mafham, M., Finan, P.J., Shelton, J., et al. (2021) Impact of the COVID-19 Pandemic on the Detection and Management of Colorectal Cancer in England: A Population-Based Study. The Lancet Gastroenterology \& Hepatology, 6, 199-208. https://doi.org/10.1016/S2468-1253(21)00005-4

[21] Greenhalgh, M., Dupley, L., Unsworth, R. and Boden, R. (2021) Where Did All the Trauma Go? A Rapid Review of the Demands on Orthopaedic Services at a UK Major Trauma Centre during the COVID-19 Pandemic. International Journal of Clinical Practice, 75, e13690. https://doi.org/10.1111/ijcp.13690

[22] Shih, C.L., Huang, P.J., Huang, H.T., Chen, C.H., Lee, T.C. and Hsu, C.H. (2021) Impact of the COVID-19 Pandemic and Its Related Psychological Effect on Orthopedic Surgeries Conducted in Different Types of Hospitals in Taiwan. Journal of Orthopaedic Surgery, 29. https://doi.org/10.1177/2309499021996072

[23] Cakici, M.C., TemIz, M.Z., IplIk, C.A., OzgOr, F., Aksoy, A.K., Ozer, M., et al. (2021) The Clinical Impact of the COVID-19 Pandemic on Daily Urological Practice: First 3 Month Multicenter Results from Istanbul. Turkish Journal of Medical Sciences.

[24] Raneri, F., Rustemi, O., Zambon, G., Del Moro, G., Magrini, S., Ceccaroni, Y., et al. (2020) Neurosurgery in Times of a Pandemic: A Survey of Neurosurgical Services during the COVID-19 Outbreak in the Veneto Region in Italy. Neurosurgical Focus, 49, E9. https://doi.org/10.3171/2020.9.FOCUS20691

[25] Ponkilainen, V., Kuitunen, I., Hevonkorpi, T.P., Paloneva, J., Reito, A., Launonen, A.P., et al. (2020) The Effect of Nationwide Lockdown and Societal Restrictions Due to COVID-19 on Emergency and Urgent Surgeries. The British Journal of Surgery, 107, e405-e406. https://doi.org/10.1002/bjs.11847

[26] Laas, D.J., Farina, Z. and Bishop, D.G. (2020) Effect of COVID-19 Pandemic Decisions on Tertiary-Level Surgical Services in Pietermaritzburg, KwaZulu-Natal Province, South Africa. South African Medical Journal, 111, 120-123. https://doi.org/10.7196/SAMJ.2020.v110i2.15332

[27] Ogundele, O.A., Omotoso, A.A. and Fagbemi, A.T. (2021) COVID-19 Outbreak: A Potential Threat to Routine Vaccination Programme Activities in Nigeria. Human Vaccines \& Immunotherapeutics, 17, 661-663. https://doi.org/10.1080/21645515.2020.1815490

[28] Orfanos, G., Al Kaisi, K., Jaiswal, A., Lim, J. and Youssef, B. (2021) The Effect of COVID-19 Pandemic on the Care of Fragility Hip Fracture Patients in the United Kingdom. A Case Control Study in a Major Trauma Centre. The Surgeon: Journal of the Royal Colleges of Surgeons of Edinburgh and Ireland. https://doi.org/10.1016/j.surge.2021.01.008

[29] Justman, N., Shahak, G., Gutzeit, O., Ben Zvi, D., Ginsberg, Y., Solt, I., et al. (2020) Lockdown with a Price: The Impact of the COVID-19 Pandemic on Prenatal Care and Perinatal Outcomes in a Tertiary Care Center. The Israel Medical Association Journal, 22, 533-537.

[30] Ayyaz, M., Butt, U.I., Umar, M., Khan, W.H., Kashif, M.R. and Hyidar, Z. (2020) Effect of COVID-19 on the Working of a Tertiary Care Hospital. Journal of the College of Physicians and Surgeons-Pakistan: JCPSP, 30, 164-167.

https://doi.org/10.29271/jcpsp.2020.supp2.S164 
[31] Korun, O., Yurdakok, O., Arslan, A., Cicek, M., Selcuk, A., Kilic, Y., et al. (2020) The Impact of COVID-19 Pandemic on Congenital Heart Surgery Practice: An Alarming Change in Demographics. Journal of Cardiac Surgery, 35, 2908-2912. https://doi.org/10.1111/jocs.14914

[32] Karia, M., Gupta, V., Zahra, W., Dixon, J. and Tayton, E. (2020) The Effect of COVID-19 on the Trauma Burden, Theatre Efficiency and Training Opportunities in a District General Hospital: Planning for a Future Outbreak. Bone \& Joint Open, 1, 494-499. https://doi.org/10.1302/2633-1462.18.BJO-2020-0074.R1 